\title{
Synthesis of iridium-based nanocomposite with catalase activity for cancer phototherapy
}

Hang Wu ${ }^{1 \dagger}$, Qi Jiang ${ }^{2 \dagger}$, Keyi Luo ${ }^{3}$, Chunping Zhu², Mengmeng Xie ${ }^{3}$, Shige Wang ${ }^{3}$, Zhewei Fei ${ }^{1 *}$ and Jiulong Zhao ${ }^{2^{*}}$

\begin{abstract}
The combination of photothermal therapy (PTT) and photodynamic therapy (PDT) has attracted attention due to its enhanced tumor therapy effect. This study proposes a novel nanoenzyme-based theranostic nanoplatform, IrO $@$ MSN@PDA-BSA(Ce6), for the combined PTT and PDT of tumors. IrO ${ }_{2}$ was prepared by a simple hydrolysis method and coated with a thin layer of mesoporous silica (MSN) to facilitate the physical adsorption of Chlorin e6 (Ce6). The PDA coating and $\mathrm{IrO}_{2} \mathrm{NPs}$ of the nanoplatform demonstrated an improved photothermal conversion efficiency of $29.8 \%$ under NIR irradiation. Further, the Ce6 loading imparts materials with the ability to produce reactive oxygen species (ROS) under $660 \mathrm{~nm}$ NIR laser irradiation. It was also proved that the $\mathrm{IrO}_{2} \mathrm{NPs}$ could catalyze the hydrogen peroxide $\left(\mathrm{H}_{2} \mathrm{O}_{2}\right)$ in the tumor microenvironment (TME) to generate endogenous oxygen $\left(\mathrm{O}_{2}\right)$, thereby enhancing the efficiency of PDT. The in vitro and in vivo experiments indicated that the nanocomposite was highly biocompatible and could produce a satisfactory tumor therapeutic effect. Thus, the findings of the present study demonstrate the viability of using theranostic nanoenzymes for translational medicine.
\end{abstract}

Keywords: Photothermal therapy, Photodynamic therapy, Cancer treatment, Biocompatibility, Iridium nanocomposite

\section{Introduction}

Cancer is currently one of the major obstacles preventing the reduction of the global mortality rate $[1,2]$. Traditional cancer treatment strategies, such as chemotherapy, radiation therapy, and surgery, result in unavoidable side effects, the development of drug resistance, and ineligibility for surgery [3-5]. The limitations of these treatments have motivated researchers to develop new cancer treatments with relatively few side effects and a high efficiency. Near-infrared light (NIR)-induced tumor

\footnotetext{
*Correspondence: zheweifei2013@sina.cn; jlzhao9@163.com

${ }^{\dagger} \mathrm{H}$ ang Wu and Qi Jiang contributed equally to this work

${ }^{1}$ Department of Breast Surgery, Xinhua Hospital, Shanghai

Jiaotong University School of Medicine, No. 1665 Kongjiang Road,

Shanghai 200433, People's Republic of China

${ }^{2}$ Department of Gastroenterology, Changhai Hospital, Second Military

Medical University, No. 168 Changhai Road, Shanghai 200433, People's Republic of China

Full list of author information is available at the end of the article
}

therapies, such as photothermal therapy (PTT) and photodynamic therapy (PDT), have attracted the attention of many researchers because they are highly effective, noninvasive, spatiotemporally controllable, and lead to relatively few side effects [6,7].

PDT involves the absorption of photon energy by a photosensitizing agent (PSA), resulting in the transfer of its electrons to the oxygen molecules $\left(\mathrm{O}_{2}\right)$ in the cancer cells. This leads to the production of a type of highly toxic reactive oxygen species (ROS, e.g., ${ }^{1} \mathrm{O}_{2}$ ) that cause irreparable damage to the cancer cells [8]. A light operative dose, reasonable PSA concentration, and adequate oxygen are necessary for effective tumor ablation. In addition, the amount of $\mathrm{O}_{2}$ directly affects the efficiency of PDT [9]. Due to the rapid and uncontrolled proliferation of tumor cells, the $\mathrm{O}_{2}$ levels in solid tumors are inadequate, thereby reducing the therapeutic efficiency of PDT $[10,11]$. Thus, researchers have proposed innovative 
strategies to enhance the $\mathrm{O}_{2}$ concentration in tumors [12]. Oxygen carriers, such as perfluorocarbon (PFC) nanoparticles NPs, can facilitate continuous oxygen supply and have been used to enhance the $\mathrm{O}_{2}$ concentration in tumors for PDT [13]. Enzyme-like substances with catalase activity have recently been used with PSA to counter hypoxia and enable ROS generation [14]. Although the $\mathrm{H}_{2} \mathrm{O}_{2}$ level in tumor microenvironment (TME) is relatively high compared to the normal tissues, the amount of endogenous $\mathrm{H}_{2} \mathrm{O}_{2}$ is still insufficient to kill the cancer cells due to the cancer cells characteristically have a high antioxidant capacity [15]. Researchers have discovered that the overexpression of $\mathrm{H}_{2} \mathrm{O}_{2}$ in TME can be utilized for the catalytic generation of endogenous $\mathrm{O}_{2}$ and facilitate tumor PDT [16, 17]. Nanoenzymes, in comparison with natural catalase, have a relatively low cost, high activity, and qualified thermostability $[18,19]$. Therefore, they can be employed to enhance the therapeutic effect of PDT.

PTT is an alternative phototherapy technique that can utilize the photothermal effects of photothermal transduction agents (PTAs) to raise the temperature of the surrounding environment and trigger the ablation and apoptosis of cancer cells [20, 21]. The application of a PTA with high biocompatibility and efficient photothermal conversion efficiency is likely to improve the efficiency of photothermal therapy [22]. Several PTAs, such as two-dimensional (2D) materials [23], noble metal materials [24], metal chalcogenide materials [25], and conjugated polymers (e.g., polydopamine (PDA) and polypyrrole (PPy)), have been synthesized in recent years $[26,27]$. However, owing to the poor performance of a single PTA, high-energy NIR laser irradiation or a relatively strong dose of PTA is required to obtain the desired treatment effect [28]. In addition, it is difficult to achieve satisfactory therapeutic activity by solely using PTT [29]. Thus, modern studies are focusing on dual-mode therapy combinations of PTT and PDT [30, 31]. The main obstacle involves building a reasonable nanoplatform to maximize the combined effects of PTT and PDT to kill tumor cells.

The application of iridium oxide $\left(\mathrm{IrO}_{2}\right)$ has recently drawn attention due to its high biocompatibility and photothermal conversion efficiency [32]. Studies have discovered that $\mathrm{IrO}_{2}$ has catalase (CAT)-like activity that enables it to catalyze $\mathrm{H}_{2} \mathrm{O}_{2}$ in the TME to generate endogenous $\mathrm{O}_{2}$, thereby enhancing the efficiency of PDT [33]. However, few studies have utilized $\mathrm{IrO}_{2}$ nanomaterial-based nanoplatform systems for the combined PTT and PDT treatment of tumors. An $\mathrm{IrO}_{2} @ M S N @ P D A-$ BSA nanocomposite was synthesized in this study for the PTT and PDT dual-mode therapeutic treatment of tumors. $\mathrm{IrO}_{2}$ was prepared by a simple hydrolysis method and coated with a thin layer of mesoporous silica (MSN) to facilitate the physical adsorption of Chlorin e6 (Ce6). The MSN layer can not only protect the oxidation of $\mathrm{IrO}_{2}$ but also provide abundant functional groups to support the further surface modification of the nanocomposite. Subsequently, PDA was coated on the surface of $\mathrm{IrO}_{2} @$ MSN, followed by the grafting of bovine serum albumin (BSA) on the surface of $\mathrm{IrO}_{2} @ \mathrm{MSN} @ P D A$ as a stabilizer. The installation of $\mathrm{IrO}_{2} @ M S N @ P D A-B S A(\mathrm{Ce} 6)$ serves several purposes. The PDA coating and $\mathrm{IrO}_{2} \mathrm{NPs}$ demonstrate significant photothermal conversion under NIR irradiation. $\mathrm{IrO}_{2} @ \mathrm{MSN} @ \mathrm{PDA}-\mathrm{BSA}(\mathrm{Ce} 6)$ can produce ROS to kill cancer cells under photon activation. $\mathrm{IrO}_{2}$ can also catalyze the decomposition of $\mathrm{H}_{2} \mathrm{O}_{2}$ to enhance the production of $\mathrm{O}_{2}$ in the TME, thereby enhancing the therapeutic effect of PDT. In vitro and in vivo experiments have proved that $\mathrm{IrO}_{2} @ \mathrm{MSN} @ P D A-B S A(\mathrm{Ce} 6)$ is biocompatible and can passively target tumors through the enhanced permeability and retention (EPR) effect, thereby harnessing the clinical and combined effects of PTT and PDT for the tumors. The design of $\mathrm{IrO}_{2} @$ MSN@PDA-BSA(Ce6) provides a framework for the design of multifunctional nanocomposite that can accurately treat cancer.

\section{Experimental section \\ Preparation and characterization of $\mathrm{IrO}_{2} @ M S N @ P D A-B S A$ and the loading of $\mathrm{Ce} 6$ \\ Synthesis of $1 \mathrm{O}_{2}$-PVP NPs}

For the synthesis of $\mathrm{IrO}_{2}$-PVP nanoparticles, first, $0.05 \mathrm{~g}$ $\mathrm{IrCl}_{3}$ and $0.1 \mathrm{~g}$ PVP were dissolved in $15 \mathrm{~mL}$ of distilled water by magnetic stirring $(400 \mathrm{rpm})$ at room temperature. Then, the solution $\mathrm{pH}$ was adjusted to 12 using $\mathrm{NaOH}$ solution $(2.0 \mathrm{M})$, and the mixture was allowed to react at $80^{\circ} \mathrm{C}$ for $12 \mathrm{~h}$ with stirring. Finally, the mixture was further separated by centrifugation $(12,000 \mathrm{rpm}$, $5 \mathrm{~min}$ ), and then rinsed three times with ethanol and distilled water. The sample in this experiment was freezedried and collected for the following usages.

\section{Synthesis of IrO $\mathrm{Z}_{2} @ M S N N P s$}

For the synthesis of $\mathrm{IrO}_{2} @ M S N$ nanoparticles, the asprepared $\mathrm{IrO}_{2}$-PVP NPs were dissolved in $65 \mathrm{~mL}$ ethanol upon ultrasonication for $30 \mathrm{~min}$. Then, $2.8 \mathrm{~mL} \mathrm{NH}_{3} \cdot \mathrm{H}_{2} \mathrm{O}$ $(28 \%)$ was added dropwise and the mixture was stirred at room temperature for $30 \mathrm{~min}$. Subsequently, $0.1 \mathrm{~mL}$ TEOS was dissolved in $6.5 \mathrm{~mL}$ ethanol and added dropwise to the mixture at a rate of $0.5 \mathrm{~mL} / \mathrm{min}$ under vigorous stirring. After stirring at room temperature for $6 \mathrm{~h}$, the obtained products were centrifuged and washed twice with ethanol and once with distilled water. To further remove the surfactant template of CTAB, the product was stirred with saturated ammonium nitrate ethanol 
solution for $12 \mathrm{~h}$. The resulting product was centrifuged, and washed it with double-distilled water extensively.

\section{Preparation of IrO $@ @ M S N @ P D A N P s$}

In this step, we dissolved $0.2 \mathrm{~g}$ dopamine in Tris buffer solution $(40 \mathrm{~mL}, 0.01 \mathrm{M}, \mathrm{pH}=8.5)$, and then mixed it with the as-prepared $\mathrm{IrO}_{2} @ M S N$ NPs. After stirring it at room temperature for $4 \mathrm{~h}$, the color of the solution changed into dark brown because of the oxidation, and the formed PDA coated $\mathrm{IrO}_{2} @ \mathrm{MSN}\left(\mathrm{IrO}_{2} @ \mathrm{MSN} @ \mathrm{PDA}\right)$ NPs were collected by centrifugation ( $8500 \mathrm{rpm}, 5 \mathrm{~min}$ ). The product was washed three times with ethanol and water to remove any possible remnants.

\section{Preparation of $1 \mathrm{rO} \mathrm{O}_{2} @ M S N @ P D A-B S A N P S$}

$\mathrm{IrO}_{2} @ \mathrm{MSN} @ P D A-B S A$ was synthesized by the amidation reaction between BSA and PDA. Specifically, the as-prepared $\mathrm{IrO}_{2} @ \mathrm{MSN} @ \mathrm{PDA}$ and $0.25 \mathrm{~g}$ BSA were added to $15 \mathrm{~mL}$ phosphate buffer $\left(\mathrm{Na}_{2} \mathrm{HPO}_{4}-\mathrm{NaH}_{2} \mathrm{PO}_{4}\right.$, $\mathrm{pH}=8.0$ ) under $4 \mathrm{~h}$ of ultrasounding at room temperature. Finally, the product was conventionally centrifuged $(13,000 \mathrm{rpm}, 10 \mathrm{~min})$ and washed it three times with distilled water.

\section{Ce6 loading of IrO ${ }_{2} @ M S N @ P D A-B S A N P S$}

For the synthesis of $\mathrm{IrO}_{2} @ \mathrm{MSN} @ P D A-\mathrm{BSA}(\mathrm{Ce} 6), \mathrm{Ce} 6$ was dissolved in DMSO at a concentration of $1000 \mu \mathrm{g} /$ mL. Afterwards, the prepared Ce6 stock solution was diluted into different concentrations and mixed with $\mathrm{IrO}_{2} @ \mathrm{MSN} @ \mathrm{PDA}-\mathrm{BSA}\left(\mathrm{IrO}_{2} @ \mathrm{MSN} @ \mathrm{PDA}-\mathrm{BSA}\right.$ finally at $1000 \mu \mathrm{g} / \mathrm{mL}$, Ce6 finally at 50,100 , and $200 \mu \mathrm{g} / \mathrm{mL}$ ). Then, the mixture was magnetically stirred overnight at room temperature. Thereafter, the reaction products were centrifuged at 12,000 rpm for 8 min to obtain $\mathrm{IrO}_{2} @$ MSN@PDA-BSA(Ce6) NPs. The supernatant containing excess Ce6 was carefully collected for the loading amount calculation of Ce6. In brief, we used UV-visNIR spectroscopy to read the absorbance at $404 \mathrm{~nm}$ of the supernatant to reckon the concentration of $\mathrm{Ce} 6$ as per the absorbance-concentration standard curve. The loading efficiency of Ce 6 was calculated by $\mathrm{W}_{\mathrm{t}} / \mathrm{W} \times 100 \%$ $\left(\mathrm{W}_{\mathrm{t}}\right.$ and $\mathrm{W}$ stand for the weight of loading Ce6 and total Ce6, respectively.), and the loading percentage of Ce6 was calculated by $\mathrm{W}_{\mathrm{t}} / \mathrm{W}_{\mathrm{S}} \times 100 \%\left(\mathrm{~W}_{\mathrm{t}}\right.$ and $\mathrm{W}_{\mathrm{s}}$ stand for the weight of loading Ce6 and the weight of $\mathrm{IrO}_{2} @$ MSN@PDA-BSA, respectively.). The amount of released Ce6 was measured by using a UV-vis spectrometer. In detail, four groups of $\mathrm{IrO}_{2} @ M S N @ P D A-B S A(C e 6)$ $(1 \mathrm{~mL}, \mathrm{Ce} 6=42.9 \mu \mathrm{g} / \mathrm{mL})$ were placed in a dialysis bag with a molecular weight cutoff of 14,000 . Then, they were dialyzed in $4 \mathrm{~mL}$ of $\mathrm{PBS}$ solution $(\mathrm{pH}=7.4)$ in a constant temperature oscillator at $37^{\circ} \mathrm{C}$ ) for $24 \mathrm{~h}$. At each predetermined time point, $2 \mathrm{~mL}$ of buffer solution that contained the released Ce6 was taken out and $2 \mathrm{~mL}$ of the corresponding fresh buffer solution was added. The concentration of the released Ce6 was determined with UV-vis-NIR spectroscopy at $404 \mathrm{~nm}$.

\section{Measurement of the dissolved oxygen content}

In this step, the catalase-like catalytic efficiency of $\mathrm{IrO}_{2} @$ MSN@PDA-BSA at different temperature $\left(37\right.$ and $\left.80{ }^{\circ} \mathrm{C}\right)$ was evaluated by mixing $\mathrm{IrO}_{2} @ \mathrm{MSN} @ P D A-B S A$ (finally concentration at $200 \mu \mathrm{g} / \mathrm{mL}$ ) with various concentration of $\mathrm{H}_{2} \mathrm{O}_{2}$ (finally at 5, 10, 20 and $50 \mu \mathrm{M}$ ). After the addition of $\mathrm{H}_{2} \mathrm{O}_{2}$, we used an oxygen probe (JPBJ-608 portable dissolved oxygen meter, Shanghai REX Instrument Factory) to monitor the dissolved oxygen content, and use a digital camera to record the bubble releasing of the reaction. At the same condition, the $\mathrm{IrO}_{2} @ \mathrm{MSN} @$ PDA without the addition of $\mathrm{H}_{2} \mathrm{O}_{2}$ was set as a control. The catalytic efficiency of $\mathrm{IrO}_{2} @ M S N @ P D A-B S A$ under simulated TME $\left(\mathrm{pH}=6.0\right.$, the concentration of $\mathrm{H}_{2} \mathrm{O}_{2}$ was about $500 \mu \mathrm{M}$ ) conditions was investigated. In details, $\mathrm{IrO}_{2} @ M S N @ P D A-B S A(200 \mu \mathrm{g} / \mathrm{mL})$ NPs were incubated in PBS solutions at different $\mathrm{pH}$ values (6.0 and 7.4) containing $500 \mu \mathrm{M} \mathrm{H}_{2} \mathrm{O}_{2}$. At predetermined time points, the generated dissolved $\mathrm{O}_{2}$ was measured by an oxygen probe (JPBJ-608 portable dissolved oxygen meter, Shanghai REX Instrument Factory).

\section{Detection of the singlet oxygen}

1,3-diphenylisobenzofuran (DPBF), a classical probe for the measurement of singlet oxygen, was employed for the detection of the singlet oxygen. Briefly, $2.95 \mathrm{~mL}$ $\mathrm{IrO}_{2} @ M S N @ P D A-B S A(\mathrm{Ce} 6)$ in dimethyl sulfoxide was mixed with $50 \mu \mathrm{L}$ DPBF in dimethyl sulfoxide. The terminal concentration of $\mathrm{IrO}_{2} @ \mathrm{MSN} @ P D A-B S A(\mathrm{Ce} 6)$ and DPBF was $20 \mu \mathrm{g} / \mathrm{mL}$ and $10 \mu \mathrm{M}$, respectively. Then, the mixture was added with $\mathrm{H}_{2} \mathrm{O}_{2}(10 \mathrm{mM}, 45 \mu \mathrm{L})$, while the mixture added with $\mathrm{H}_{2} \mathrm{O}(45 \mu \mathrm{L})$ was set as the control group. We exposed the above solutions to a $660 \mathrm{~nm}$ NIR laser $\left(0.3 \mathrm{~W} / \mathrm{cm}^{2}\right)$ in a dark environment for $20 \mathrm{~min}$, and used the UV-vis-NIR spectrophotometer (Lambda 25, PerkinElmer, USA) to record the absorption intensity at designed time intervals.

\section{Photothermal conversion performance}

In order to explore the photothermal conversion performance, the as-prepared $\mathrm{IrO}_{2} @ M S N @ P D A-B S A(C e 6)$ was prepared in different concentrations $(0,100,250$ and $500 \mu \mathrm{g} / \mathrm{mL}$ in saline). Then, $100 \mu \mathrm{L}$ of the above samples were added in each well of a 96-well plate and exposed to the $808 \mathrm{~nm}$ NIR laser $\left(1 \mathrm{~W} / \mathrm{cm}^{2}, 5 \mathrm{~min}\right)$. To investigate the power density-dependent thermal characteristics, $\mathrm{IrO}_{2} @ \mathrm{MSN} @ P D A-B S A(\mathrm{Ce} 6)$ with the concentration of $200 \mu \mathrm{g} / \mathrm{mL}$ was select to be irradiated with $808 \mathrm{~nm}$ 
NIR laser at different power $\left(0.5,0.8\right.$ and $\left.1 \mathrm{~W} / \mathrm{cm}^{2}\right)$ for 5 min. The photothermal stability of $\mathrm{IrO}_{2} @ \mathrm{MSN} @ P D A-$ $\mathrm{BSA}(\mathrm{Ce} 6)$ was also validated via the $808 \mathrm{~nm}$ NIR laser irradiation $\left(1 \mathrm{~W} / \mathrm{cm}^{2}\right)$ for 5 on/off cycles (laser on for $10 \mathrm{~min}$ and laser off for $10 \mathrm{~min}$ in each cycle). We use FLIR $^{\mathrm{TM}}$ E60 camera (FLIR, USA) to record the temperature increment $(\Delta \mathrm{T})$ of the above experiment for specific analysis.

\section{In vitro cellular viability}

In this section, L929 cells were chosen to assess the potential cellular cytotoxicity of $\mathrm{IrO}_{2} @ M S N @ P D A-B S A$ in vitro. On the one hand, the CCK8 kit was performed to detect the cell viability after cultured with $\mathrm{IrO}_{2} @ M S N @$ PDA-BSA(Ce6). In brief, L929 cells were seeded into 96-well plate (8000 cells/well) and maintained at $37{ }^{\circ} \mathrm{C}$ in a humidified atmosphere with $5 \% \mathrm{CO}_{2}$. After $24 \mathrm{~h}$, the medium was replaced by various concentrations $(100 \mu \mathrm{L}$, 0, 50, 100, 250 and $500 \mu \mathrm{g} / \mathrm{mL}$ in RMPI1640) of $\mathrm{IrO}_{2} @$ MSN@PDA-BSA(Ce6). Another 24 h later, $100 \mu \mathrm{L}$ fresh RMPI1640 with $10 \mu \mathrm{L}$ CCK8 test solution was added in each tested well to replace the old solution and then incubated for another $2 \mathrm{~h}$. Using a microplate reader to read the absorbency of each well at $450 \mathrm{~nm}$ to calculate cell viability. On the other hand, calcein-AM/PI Live/Dead kit was used to further determine the cytocompatibility of $\mathrm{IrO}_{2} @ \mathrm{MSN} @ P D A-B S A(\mathrm{Ce} 6)$. L929 cells were cultured and disposed of with the same as the CCK8 assay but lastly stained with calcein-AM/PI $(100 \mu \mathrm{L})$ based on the manufacturer for $30 \mathrm{~min}$ at $37^{\circ} \mathrm{C}$. The counterstained cellular morphology was recorded using a fluorescence microscope (Olympus BX53).

\section{In vitro tumor therapy}

To study the cytotoxic effects of $\mathrm{IrO}_{2} @ M S N @ P D A-$ $\mathrm{BSA}(\mathrm{Ce} 6)$ in vitro, HT29 cells were seeded into 96-well plates at a density of $8 \times 10^{3}$ cells/well and maintained in a humidified cell-incubator with $5 \% \mathrm{CO}_{2}$ at $37{ }^{\circ} \mathrm{C}$ overnight for cell attachment. Then, each well was filled with $100 \mu \mathrm{L} \mathrm{IrO}_{2} @ M S N @ P D A-B S A(C e 6)$ (in DMEM, 200 g/ $\mathrm{mL}$ ) and continue culturing for $12 \mathrm{~h}$. Then, we divided cells into four groups $(n=6)$. Cells in group 2 were irradiated with $808 \mathrm{~nm}$ laser $\left(1 \mathrm{~W} / \mathrm{cm}^{2}, 5 \mathrm{~min}\right)$ to assess the effect of PTT. Cells in group 3 were exposed to 660 $\mathrm{nm}$ laser $\left(0.3 \mathrm{~W} / \mathrm{cm}^{2}, 3 \mathrm{~min}\right)$ and cells in group 4 were treated with the medium containing $\mathrm{H}_{2} \mathrm{O}_{2}(100 \mu \mathrm{mol} / \mathrm{L})$ and the $\mathrm{pH}$ was adjusted to 6.0 with $\mathrm{HCl}$. Cells in group 5 were exposed to a combined NIR irradiation, including $808 \mathrm{~nm}\left(1 \mathrm{~W} / \mathrm{cm}^{2}\right)$ for $5 \mathrm{~min}$ and $660 \mathrm{~nm}\left(0.3 \mathrm{~W} / \mathrm{cm}^{2}\right)$ for 3 min. Cells treated with DMEM without other intervention were set as the control (group 1). Finally, we used CCK- 8 and the calcein-AM/PI Live/Dead staining to evaluate the relative viabilities of cells.

\section{In vitro hemocompatibility}

The hemocompatibility of $\mathrm{IrO}_{2} @ M S N @ P D A-B S A(\mathrm{Ce} 6)$ was investigated by the typical in vitro hemolysis assay as below: fresh complete blood samples $(1 \mathrm{~mL})$ were collected from healthy KM mice and centrifuged (3000 rpm, $3 \mathrm{~min}, 4^{\circ} \mathrm{C}$ ) to obtain the mouse red blood cells (mRBCs). After that, the harvested mRBCs were washed with PBS three times and reposited in PBS for further experiments. Then, the above mRBCs dispersions $(0.3 \mathrm{~mL})$ was mixed with $1 \mathrm{~mL}$ of different concentrations (100, 250 and $500 \mu \mathrm{g} / \mathrm{mL}$ ) of $\mathrm{IrO}_{2} @ M S N @ P D A-B S A$ and cultured at $37^{\circ} \mathrm{C}$. Meanwhile, $\mathrm{mRBCs}$ dispersions $(0.3 \mathrm{~mL})$ were incubated with $1 \mathrm{~mL}$ of PBS (negative control) or $1 \mathrm{~mL}$ of DI water (positive control). After incubating for $4 \mathrm{~h}$, the supernatant of the above mixture was gathered via centrifugation $(12,000 \mathrm{rpm}, 5 \mathrm{~min})$. Subsequently, we recorded the absorbance of the supernatants at $580 \mathrm{~nm}$ to compute the hemolysis percentage (HP) according to literature.

\section{In vivo biocompatibility and biodistribution}

To evaluate the biocompatibility and biodistribution of $\mathrm{IrO}_{2} @ \mathrm{MSN} @ \mathrm{PDA}-\mathrm{BSA}(\mathrm{Ce} 6)$ in vivo, the healthy KM female mice (SPF grade) were randomly sent into two groups ( $n=24$ per group). All animal experiments were conducted under the protocols approved by the Laboratory Animal Center of Changhai Hospital of Second Military Medical University, the policies of National Ministry of Hkiuealth. One group was intravenously (I.V.) injected with saline as a control, another group was injected with $\mathrm{IrO}_{2} @ \mathrm{MSN} @ \mathrm{PDA}-\mathrm{BSA}(\mathrm{Ce} 6)$ solution $(250 \mu \mathrm{L}, 1 \mathrm{mg} / \mathrm{mL}$ in PBS). The body weight of all experimental mice was weighed and recorded per 2 days. Mice were heart punctured for collect blood samples after anesthesia on 1, 7 , 28 days and then were euthanized for organs collection. The blood samples were used for blood routine analysis and blood biochemical index testing in virtue of a Sysmex XS-800i automated hematology analyzer and a DxC 800 automatic biochemical analyzer. These crucial organs (heart, lung, liver, kidney, and spleen) were partly sectioned and immediately dipped in $4 \%$ polyformaldehyde for hematoxylin and eosin (H\&E) staining. Besides, the remaining part of the organs was used for quantitative detection of the Silicon $(\mathrm{Si})$ ion biodistribution through the Agilent 700 Series ICP-OES.

\section{In vivo tumor therapy}

HT29 cells $\left(10^{7}\right.$ cells per mouse, in $150 \mu \mathrm{L}$ of serumfree DMEM) were subcutaneously implanted into the right back of the Balb/c nude mice (female, 4-6 weeks old). Three weeks after the cell-injection, a tumor nodule about $0.15-0.20 \mathrm{~cm}^{3}$ in each mouse was established. Then, the tumor mice were randomly allocated to five 
groups with six mice in each group as follows: mice in group 1 were I.V. injected with saline and served as the control group. Mice in group 2 were given with $\mathrm{IrO}_{2} @$ MSN@PDA-BSA(Ce6) solution (200 $\mu \mathrm{L}, 1 \mathrm{mg} / \mathrm{mL}$ in PBS, I.V.) for PTT. Mice in group 3 were treated with $\mathrm{IrO}_{2} @ M S N @ P D A-B S A(C e 6)$ solution $(200 \mu \mathrm{L}, 1 \mathrm{mg} /$ $\mathrm{mL}$ in PBS, I.V.) for PDT. With regard to the dual-modal tumor therapy, $200 \mu \mathrm{L}$ (I.V.) and $20 \mu \mathrm{L}$ (I.T.) $\mathrm{IrO}_{2} @$ MSN@PDA-BSA(Ce6) were separately injected in group 4 and group 5. Twelve hours after the injection, mice in group 1 and group 2 were irradiated with $808 \mathrm{~nm}$ NIR laser $\left(1.0 \mathrm{~W} / \mathrm{cm}^{2}\right)$ for $5 \mathrm{~min}$, while mice in group 3 were subjected to the $660 \mathrm{~nm}$ laser $\left(0.3 \mathrm{~W} / \mathrm{cm}^{2}\right)$ for $5 \mathrm{~min}$. As the combined treatment group, the mice in group 4 and group 5 were successively exposed to $808 \mathrm{~nm}$ NIR laser $\left(1.0 \mathrm{~W} / \mathrm{cm}^{2}\right)$ and $660 \mathrm{~nm}$ laser $\left(0.3 \mathrm{~W} / \mathrm{cm}^{2}\right)$ for $5 \mathrm{~min}$. The FLIR E60 infrared camera was exploited to keep the record of $\Delta \mathrm{T}$ measurement and thermal imaging during the treatments. Mice in all groups were then raised for 4 weeks, and we measured the tumor volume every 3 days. The efficiency of in vivo tumor treatment was assessed by the relative tumor volume.

\section{Statistical analysis}

All the data acquest from the above experiments were reported as mean \pm standard deviation (SD) and statistically analyzed with one-way ANOVA. P values $<0.05$ was regard as statistically significant. Data indicated with $\left(^{*}\right)$ deputize for $\mathrm{p}<0.05$, $\left(^{* *}\right)$ for $\mathrm{p}<0.01$, and ${ }^{(* * *)}$ for $\mathrm{p}<0.001$.

\section{Results and discussions}

Synthesis and characterization of $\mathrm{IrO}_{2} @ M S N @ P D A-B S A$

Colloidal-stable polyvinylpyrrolidone (PVP)-decorated $\mathrm{IrO}_{2} \mathrm{NPs}\left(\mathrm{IrO}_{2}\right.$-PVP) were prepared through facile hydrolysis of $\mathrm{IrCl}_{3}$, the as-prepared $\mathrm{IrO}_{2}$-PVP nanoparticles showed a diameter of approximately $(10.12 \pm 2.10)$ nm (Additional file 1: Fig. S1). Then the as-prepared nanoparticles were coated with a thin layer of MSN to carry Ce6 through physical adsorption. PDA was then coated on the surfaces of the $\mathrm{IrO}_{2} @ M S N$ particles under alkaline conditions because DA self-polymerizes to form PDA. A BSA modifier was grafted onto the $\mathrm{IrO}_{2} @$ MSN@PDA surface under ultrasonic conditions through an amidation reaction between the $-\mathrm{COOH}$ group of BSA and the $-\mathrm{NH}_{2}$ group of PDA in a buffered solution of $\mathrm{Na}_{2} \mathrm{HPO}_{4}-\mathrm{NaH}_{2} \mathrm{PO}_{4}$ to achieve colloidal stability (Scheme 1). The morphology of the product was analyzed using SEM and TEM. A spherical shape with an average diameter of approximately $84 \pm 13 \mathrm{~nm}$ (Fig. 1a, b) was obtained. Therefore, we can conclude that NPs have a certain degree of aggregation, which is attributed to the interaction between the PDA and BSA that were grafted onto the NPs. The preparation of samples for SEM and TEM may have resulted in NP aggregation as well. The hydration kinetic diameter and Tyndall effect of the IrO $\mathrm{I}_{2} @ \mathrm{MSN} @ P D A-B S A$ NPs in distilled water and PBS remained constant and clearly visible after $12 \mathrm{~h}$ of storage. This indicates that the surface-modified BSA endows durable colloidal stability to the $\mathrm{IrO}_{2} @ \mathrm{MSN} @$ PDA-BSA NPs in different solutions. The difference in size of this nanocomposite between TEM and DLS may be due to the fact that the size measured by DLS is the hydration kinetic diameter: the BSA leads to the formation of a swollen structure with a high water content. The absence of vascular supportive tissues in tumors results in the formation of leaky vessels with pores $(200 \mathrm{~nm}$ to $1.2 \mu \mathrm{m}$ in diameter) and leads to poor lymphatic drainage, which is the structural basis of the enhanced permeability and retention (EPR) effect. The EPR effect of the nanomedicine with larger size was lower than the most suitable size but it also can accumulate in tumor through EPR effect. EDS (Additional file 1: Fig. S2) and elemental mapping (Fig. 1d-f) confirmed the coexistence of $\mathrm{O}$, $\mathrm{Si}$, and Ir. Nitrogen adsorption-desorption isotherms were used to investigate the porous structure (Fig. 1g). The results indicated that the $\mathrm{IrO}_{2} @ M S N @ P D A-B S A$ NPs had a high specific surface area $\left(149.6521 \mathrm{~m}^{2} / \mathrm{g}\right)$ and large pore volume $\left(0.2 \mathrm{~cm}^{3} / \mathrm{g}\right)$. The average pore size was $5.7 \mathrm{~nm}$ (Fig. 1h). The XRD results of the $\mathrm{IrO}_{2} @ M S N @$ PDA-BSA NPs (Fig. 1i) did not contain typical diffraction peaks, indicating the poor crystalline state of the NPs. The chemical structure of $\mathrm{IrO}_{2} @ M S N @ P D A-B S A ~ N P s$ was determined through FTIR. The absorption peak at $1089 \mathrm{~cm}^{-1}$ represents the tensile and asymmetric vibration of Si-O-Si (Additional file 1: Fig. S3), indicating the existence of $\mathrm{SiO}_{2}$ in the $\mathrm{IrO}_{2} @ M S N @ P D A-B S A$ NPs. The vibration at $1422 \mathrm{~cm}^{-1}$ is attributed to the $-\mathrm{COOH}$ group of BSA. The vibration signals at $1640 \mathrm{~cm}^{-1}$ and $1500 \mathrm{~cm}^{-1}$ are attributed to the deformation vibrations of amide I $\left(-\mathrm{NH}_{2}\right)$ and amide II $(-\mathrm{NH}-)$ of BSA, respectively. The vibration peaks of the PDA and BSA amide groups due to the stretching of the $-\mathrm{NH}-$ group are located at $3400 \mathrm{~cm}^{-1}$ and $3000 \mathrm{~cm}^{-1}$, respectively. The peaks corresponding to the $-\mathrm{C}=\mathrm{C}-$ stretching vibration of PDA is located at $1500 \mathrm{~cm}^{-1}$. These results collectively confirm that PDA and BSA were successfully decorated onto the $\mathrm{IrO}_{2} @ M S N$ surface. The yields of $\mathrm{IrO}_{2}-\mathrm{PVP}$, $\mathrm{IrO}_{2} @ \mathrm{MSN}, \mathrm{IrO}_{2} @ \mathrm{MSN} @ \mathrm{PDA}-\mathrm{BSA}, \mathrm{IrO}_{2} @ \mathrm{MSN} @ \mathrm{PDA}-$ BSA were $89.3 \%, 78.6 \%, 73.2$ and $68.4 \%$, respectively.

\section{Ce6 loading}

The conspicuous pore sizes of the $\mathrm{IrO}_{2} @ \mathrm{MSN} @ \mathrm{PDA}-$ BSA NPs are likely to facilitate guest molecule loading. A classical PSA named Ce6 was chosen as the model drug to be physically adsorbed in the mesoporous pore of 


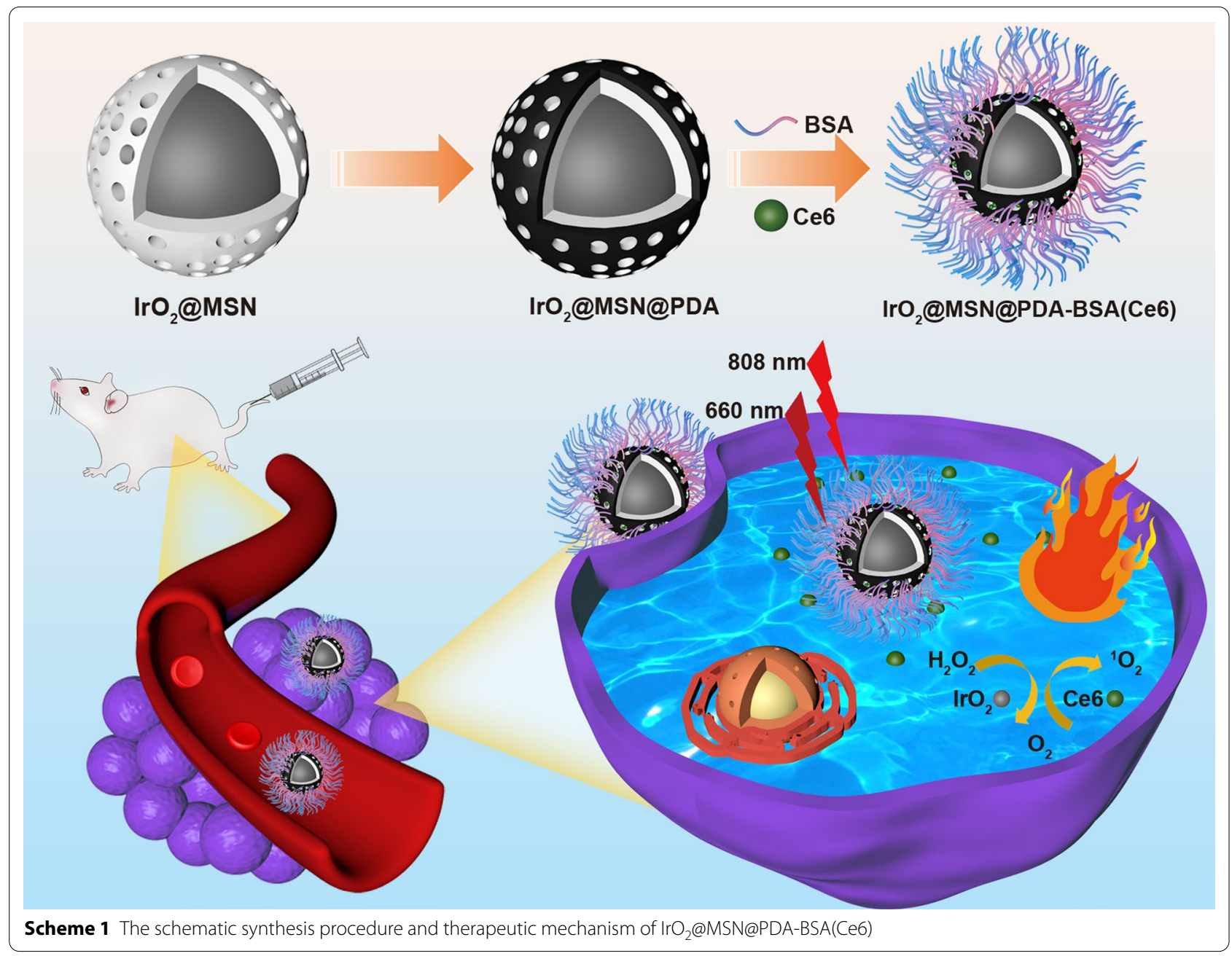

MSN. It is essential to evaluate the loading performance of $\mathrm{IrO}_{2} @ M S N @ P D A-B S A$ because the tumor PDT is dose-dependent. The UV-vis-NIR spectra of $\mathrm{IrO}_{2} @$ MSN@PDA-BSA before and after the loading of Ce6 are shown in Fig. 2b. The NPs carrying Ce6 have two typical characteristic peaks at $404 \mathrm{~nm}$ and $665 \mathrm{~nm}$, in comparison to the spectrum of the pure $\mathrm{IrO}_{2} @ M S N @ P D A-B S A$. This proves that $\mathrm{Ce} 6$ was successfully loaded onto $\mathrm{IrO}_{2} @$ MSN@PDA-BSA. The Ce6 loading of $\mathrm{IrO}_{2} @ M S N @ P D A-$ BSA was then optimized by varying the concentration of Ce6. Ce6 concentrations of 50, 100, and $200 \mu \mathrm{g} / \mathrm{mL}$ resulted in Ce6 loading values of approximately $76.3 \%$, $61.3 \%$, and $43.0 \%$ on $\mathrm{IrO}_{2} @ \mathrm{MSN} @ \mathrm{PDA}-\mathrm{BSA}$, respectively. The $\mathrm{Ce} 6$ loading ratio was calculated by dividing the weight of the loaded $\mathrm{Ce} 6$ with the weight of $\mathrm{IrO}_{2} @$ MSN@PDA-BSA, which was equal to 3.8\%,6.1\%, and $8.6 \%$ at Ce6 concentrations of 50, 100, and $200 \mu \mathrm{g} / \mathrm{mL}$, respectively (Fig. 2c). According to the abovementioned results, a Ce6 concentration of $200 \mu \mathrm{g} / \mathrm{mL}$ was selected for the subsequent experiments. The in vitro $\mathrm{Ce} 6$ release behavior of $\mathrm{IrO}_{2} @ \mathrm{MSN} @ \mathrm{PDA}-\mathrm{BSA}(\mathrm{Ce} 6)$ was thoroughly evaluated. As shown in Additional file 1: Fig.S4, the Ce6 release percentages were lower than $12 \%$ under the tested conditions $\left(\mathrm{pH}=7.4, \mathrm{~T}=37{ }^{\circ} \mathrm{C}\right)$, thereby guaranteeing the secure and effective use of Ce6.

\section{Catalytic efficiency and ${ }^{1} \mathrm{O}_{2}$ generating capacity}

$\mathrm{IrO}_{2} @ M S N @ P D A-B S A$ can improve the PDT efficiency by catalyzing the decomposition of $\mathrm{H}_{2} \mathrm{O}_{2}$ to generate endogenous $\mathrm{O}_{2}$ due to the catalase-like activity of $\mathrm{IrO}_{2}$. The addition of $\mathrm{H}_{2} \mathrm{O}_{2}$ to the $\mathrm{IrO}_{2} @ M S N @ P D A-B S A$ solution results in the immediate generation of several $\mathrm{O}_{2}$ bubbles, as shown in Fig. 2d. This intuitively confirms the catalytic ability of $\mathrm{IrO}_{2}$. Further, the catalytic efficiency of $\mathrm{IrO}_{2} @ M S N @ P D A-B S A$ was concentration-dependent. An increase in the $\mathrm{IrO}_{2} @ \mathrm{MSN} @ P D A-B S A$ concentration led to an increase in the concentration of the dissolved $\mathrm{O}_{2}$ (Fig. 2e). In addition, we investigate the catalytic efficiency of $\mathrm{IrO}_{2} @ \mathrm{MSN} @ \mathrm{PDA}-\mathrm{BSA}$ under simulated TME $\left(\mathrm{pH}=6.0\right.$, the concentration of $\mathrm{H}_{2} \mathrm{O}_{2}$ was about 500 


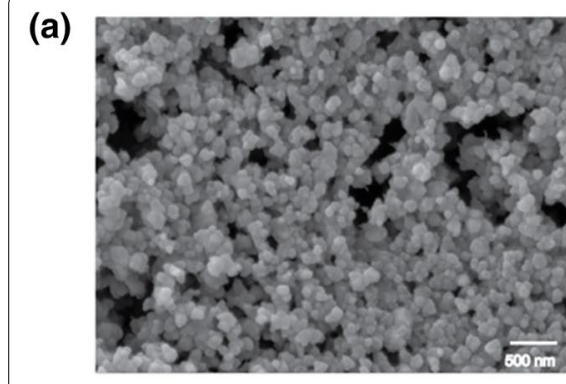

(d)

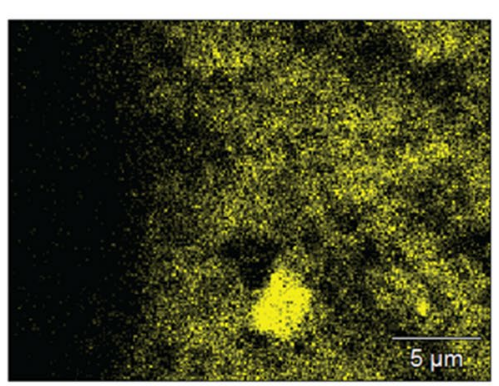

(g)

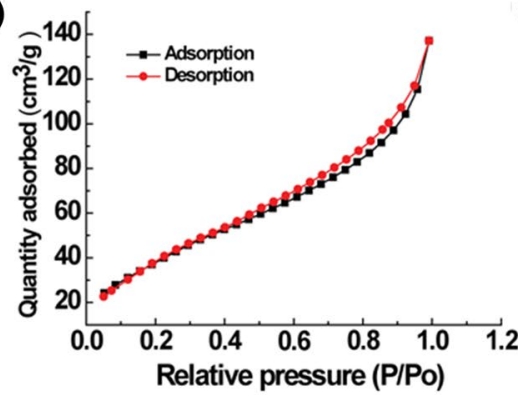

(b)

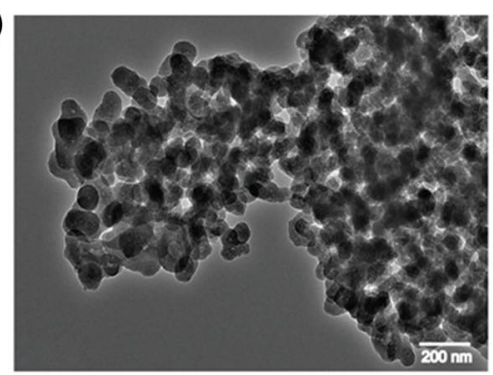

(e)

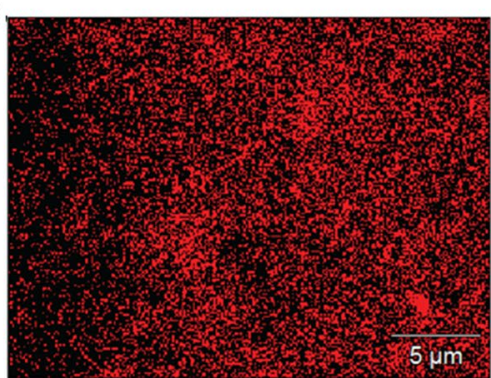

(h)

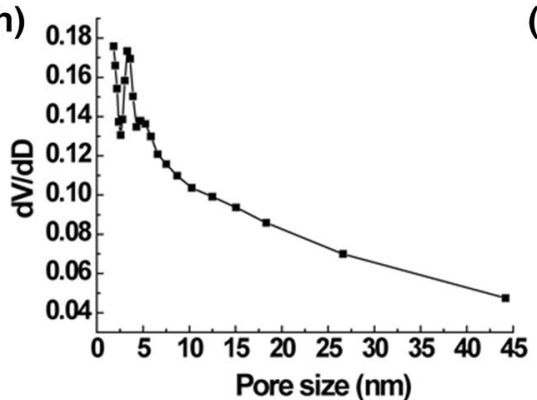

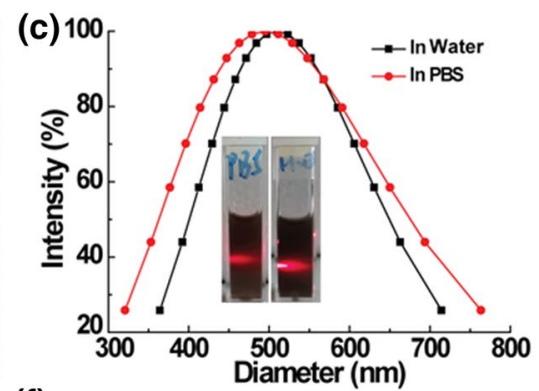

(f)

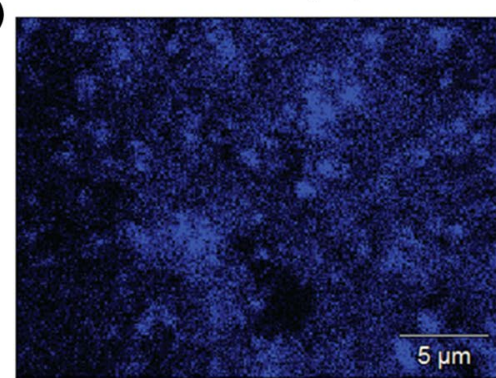

(i)

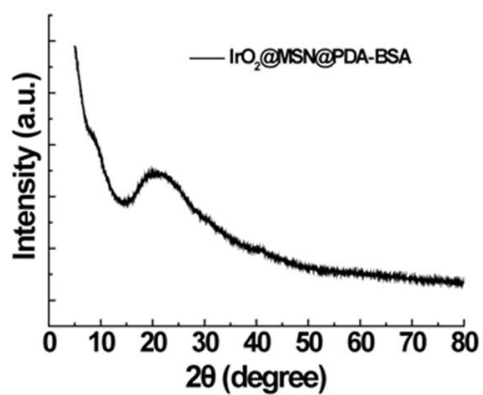

Fig. 1 Characterization of IrO $@ M S N @ P D A-B S A$ NPS. a SEM; b TEM; $\mathbf{c}$ dynamic light scattering and solution photos (left: in PBS, right: in water); d-f elemental distribution mappings ( $\mathrm{d}, \mathrm{O} ; \mathrm{e}, \mathrm{Si} ; \mathrm{f}, \mathrm{r}$ ); $\mathbf{g}$ nitrogen adsorption-desorption isotherm; $\mathbf{h}$ pore size of IrO ${ }_{2} @ M S N @ P D A-B S A ; \mathbf{i}$ XRD pattern

$\mu \mathrm{M})$ conditions. As shown in Additional file 1: Fig. S4, although the content of generated oxygen decreased with the decrease of the solution $\mathrm{pH}$, there was still a significant difference as compared to PBS with $\mathrm{H}_{2} \mathrm{O}_{2}$ at $\mathrm{pH}$ 6.0. The $\mathrm{IrO}_{2} @ M S N @ P D A-B S A$ NPs possess the required thermal stability and are superior to the traditional catalase, which is vulnerable to hyperthermia (Fig. $2 \mathrm{~g}$ ). The catalytic ability of $\mathrm{IrO}_{2} @ M S N @ P D A-B S A$ was satisfactory at $37{ }^{\circ} \mathrm{C}$ and highly dependent on the substrate concentration (Fig. 2f). The catalytic ability of $\mathrm{IrO}_{2} @ \mathrm{MSN} @$ PDA-BSA remained constant even after increasing the temperature to $80^{\circ} \mathrm{C}$.

The amount of ${ }^{1} \mathrm{O}_{2}$ contained in the solution was measured through light radiation to verify whether the $\mathrm{O}_{2}$ generated by $\mathrm{IrO}_{2} @ \mathrm{MSN} @ P D A-B S A$ could be utilized to enhance the tumor PDT. The irradiation of the $\mathrm{IrO}_{2} @$ MSN@PDA-BSA solution led to a reduction in the light absorption by the DPBF, thereby confirming the generation of ${ }^{1} \mathrm{O}_{2}\left({ }^{1} \mathrm{O}_{2}\right.$ can oxidize the probe of DPBF and catalyze its discoloring reaction). In addition, it was observed that the rate of reduction in the light absorption increased with the addition of $\mathrm{H}_{2} \mathrm{O}_{2}$ (Fig. 2 h). This confirms the ability of the $\mathrm{IrO}_{2} @ M S N @ P D A-B S A$ NPs to enhance ${ }^{1} \mathrm{O}_{2}$ generation in the presence of $\mathrm{H}_{2} \mathrm{O}_{2}$. The improved ${ }^{1} \mathrm{O}_{2}$ generation indicates that $\mathrm{IrO}_{2} @ M S N @$ PDA-BSA can be used as an intelligent nanozyme system to facilitate tumor PDT in the TME.

\section{Photothermal conversion performance}

In addition to enhancing the tumor PDT, IrO $\mathrm{I}_{2} @ \mathrm{MSN} @$ PDA-BSA is a PTA that can be used in the PTT of tumors. The absorbance capacity of $\mathrm{IrO}_{2} @ M S N @ P D A-$ BSA for wavelengths ranging from 400 to $1000 \mathrm{~nm}$ was first studied. IrO $\mathrm{O}_{2} @ \mathrm{MSN} @ P D A-B S A$ demonstrated a high light absorbance capacity, and the light absorbance increased with increasing NP concentration in the abovementioned wavelength range (Fig. 2i). The absorbed light was partially transformed into heat. The photothermal ability of $\mathrm{IrO}_{2} @ \mathrm{MSN} @ P D A-B S A$ was studied by varying the NIR laser power and NP concentration. The $\Delta \mathrm{T}$ 


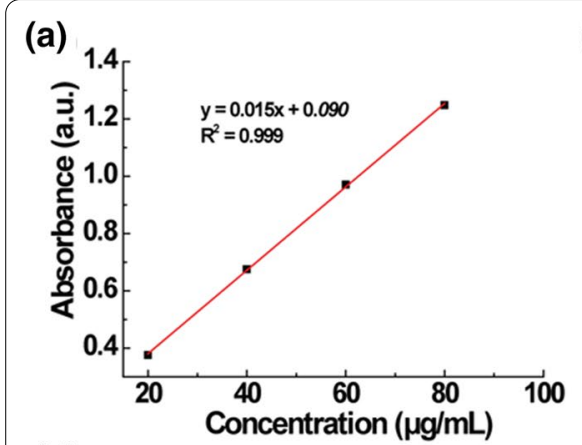

(d)

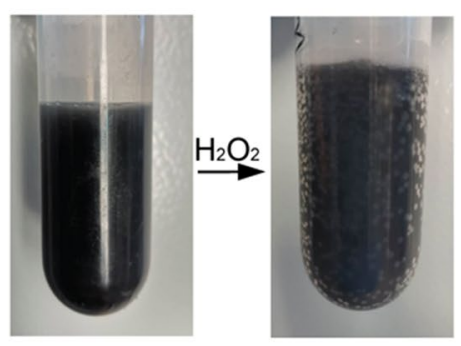

(g)

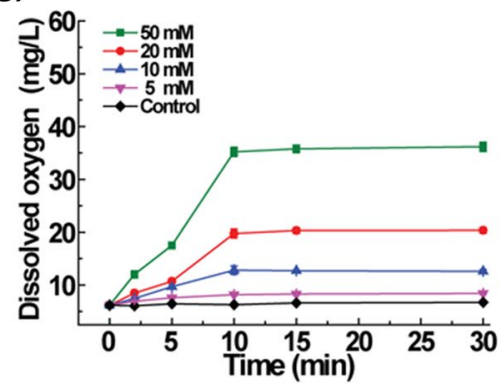

(b)

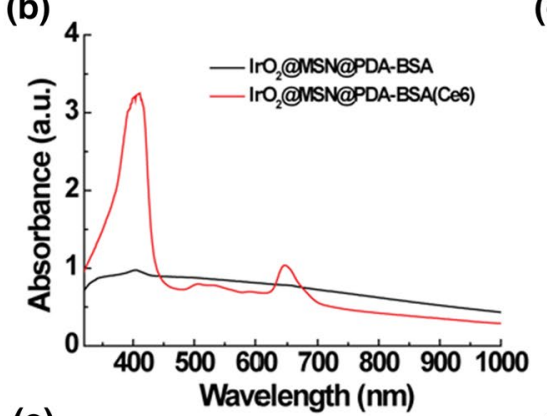

(e)

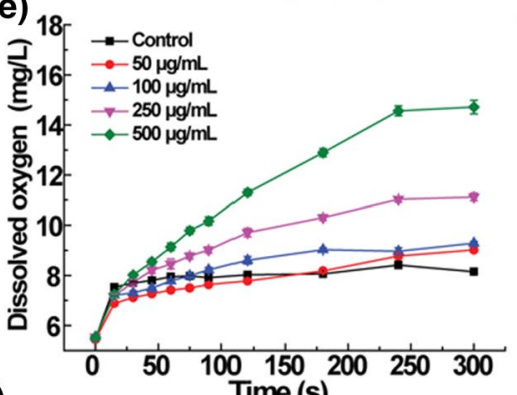

(h)

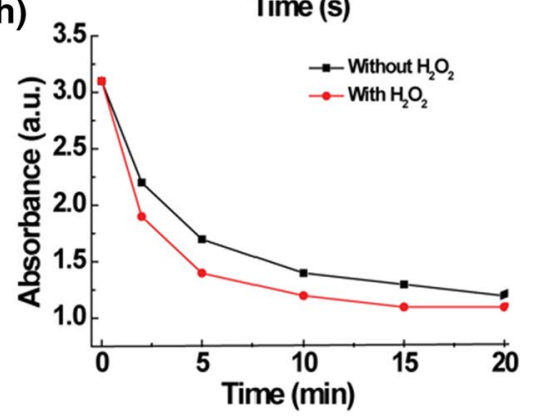

(c)

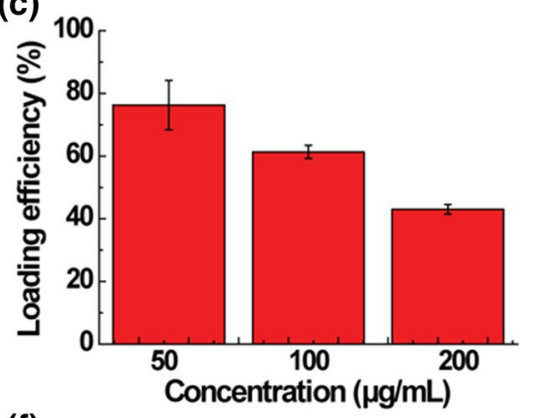

(f)

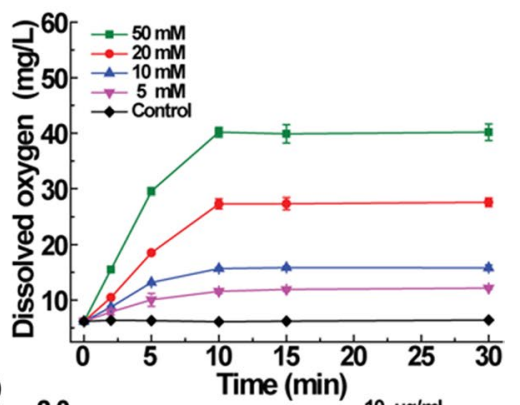

(i)

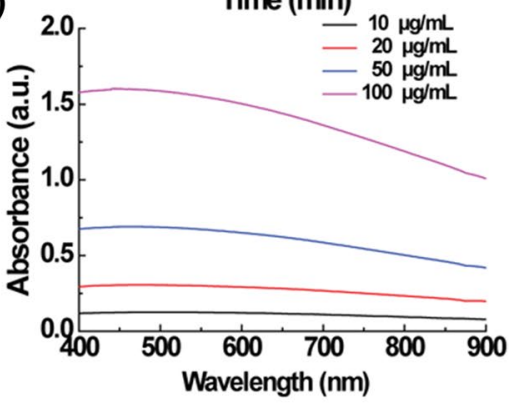

Fig. 2 a Standard curve of Ce6; b light absorption of IrO ${ }_{2} @ M S N @ P D A-B S A$ and IrO ${ }_{2} @ M S N @ P D A-B S A(C e 6) ;$ c Ce6 loading efficiency of IrO $2 @ M S N @$ PDA-BSA (1000 $\mathrm{\mu g} / \mathrm{mL})$ under different Ce6 concentrations; $\mathbf{d}$ photographs of $1 \mathrm{rO} \mathrm{O}_{2} @ M S N @ P D A-B S A$ solutions before and after the addition of $\mathrm{H}_{2} \mathrm{O}_{2}$; e $\mathrm{O}_{2}$ generation ability of IrO $\mathrm{O}_{2} @ M$ MNN@PDA-BSA with different concentrations; $\mathbf{f}, \mathbf{g} \mathrm{O}_{2}$ generation ability of IrO $_{2} @ M$ MSN@PDA-BSA solutions at $\mathbf{f} 37^{\circ} \mathrm{C}$ and $\mathbf{g} 80^{\circ} \mathrm{C}$ with various concentrations of $\mathrm{H}_{2} \mathrm{O}_{2} ; \mathbf{h}$ the light absorption of $\mathrm{IrO}_{2} @ M S N @ P D A-B S A(C e 6)$ with or without the addition of $\mathrm{H}_{2} \mathrm{O}_{2} ; \mathbf{i} U V-v i s$ spectra of $1 \mathrm{rO} \mathrm{I}_{2} @ M S N @ P D A-B S A$ NPs solutions

of $\mathrm{IrO}_{2} @ \mathrm{MSN} @ \mathrm{PDA}-\mathrm{BSA}$ increased with the increasing concentration of the solution at a fixed power density, as shown in Fig. 3a. However, the $\Delta \mathrm{T}$ of water was negligible. The $\Delta \mathrm{T}$ values of the solutions at concentrations of 100,250 , and $500 \mathrm{mg} / \mathrm{mL}$ were $7.0,16.4$, and $30.2^{\circ} \mathrm{C}$, respectively. $\mathrm{IrO}_{2} @ \mathrm{MSN} @ \mathrm{PDA}-\mathrm{BSA}$ was then used at a concentration of $250 \mathrm{mg} / \mathrm{mL}$ to study the impact of power density on heat production. The $\Delta \mathrm{T}$ values of $\mathrm{IrO}_{2} @ \mathrm{MSN} @ P D A-B S A$ were $7.7,12.6$, and $16.4{ }^{\circ} \mathrm{C}$ at power densities of $0.5,0.8$, and $1.0 \mathrm{~W} / \mathrm{cm}^{2}(808 \mathrm{~nm})$, respectively. An E60 thermal imaging camera (FLIR Systems, Inc., USA) was used to record the concentration, irradiation, and laser-power-density-dependent temperature surges of $\mathrm{IrO}_{2} @ \mathrm{MSN} @ P D A-B S A$ (Fig. 3b, d). It was confirmed that the photothermal ability of $\mathrm{IrO}_{2} @ M S N @$ PDA-BSA was dependent on the material concentration and laser power density. The photothermal conversion efficiency and heat transfer time constant (ts) were equal to $29.8 \%$ and $175.7 \mathrm{~s}$, both of which are comparable to the values obtained for graphene and black phosphorus nanosheets (Fig. 3f, g) [34, 35]. $\mathrm{IrO}_{2} @ M S N @ P D A-B S A$ is considered photothermally stable because its $\Delta \mathrm{T}$ variation during the five rounds of NIR laser irradiation substantial (Fig. 3e).

\section{In vitro biocompatibility assay}

In vitro biocompatibility, including cytocompatibility and hemocompatibility, is an essential factor in the biomedical applications of nanomaterials. Therefore, the cytocompatibility of $\mathrm{IrO}_{2} @ \mathrm{MSN} @ P D A-B S A(\mathrm{Ce} 6)$ was assessed using a CCK- 8 cell viability assay and calcein-AM/PI double staining. The cell viabilities were maintained above $95 \%$ after $24 \mathrm{~h}$ of co-cultivation with varying concentrations of $\mathrm{IrO}_{2} @ \mathrm{MSN} @ \mathrm{PDA}-\mathrm{BSA}(\mathrm{Ce} 6)$, 


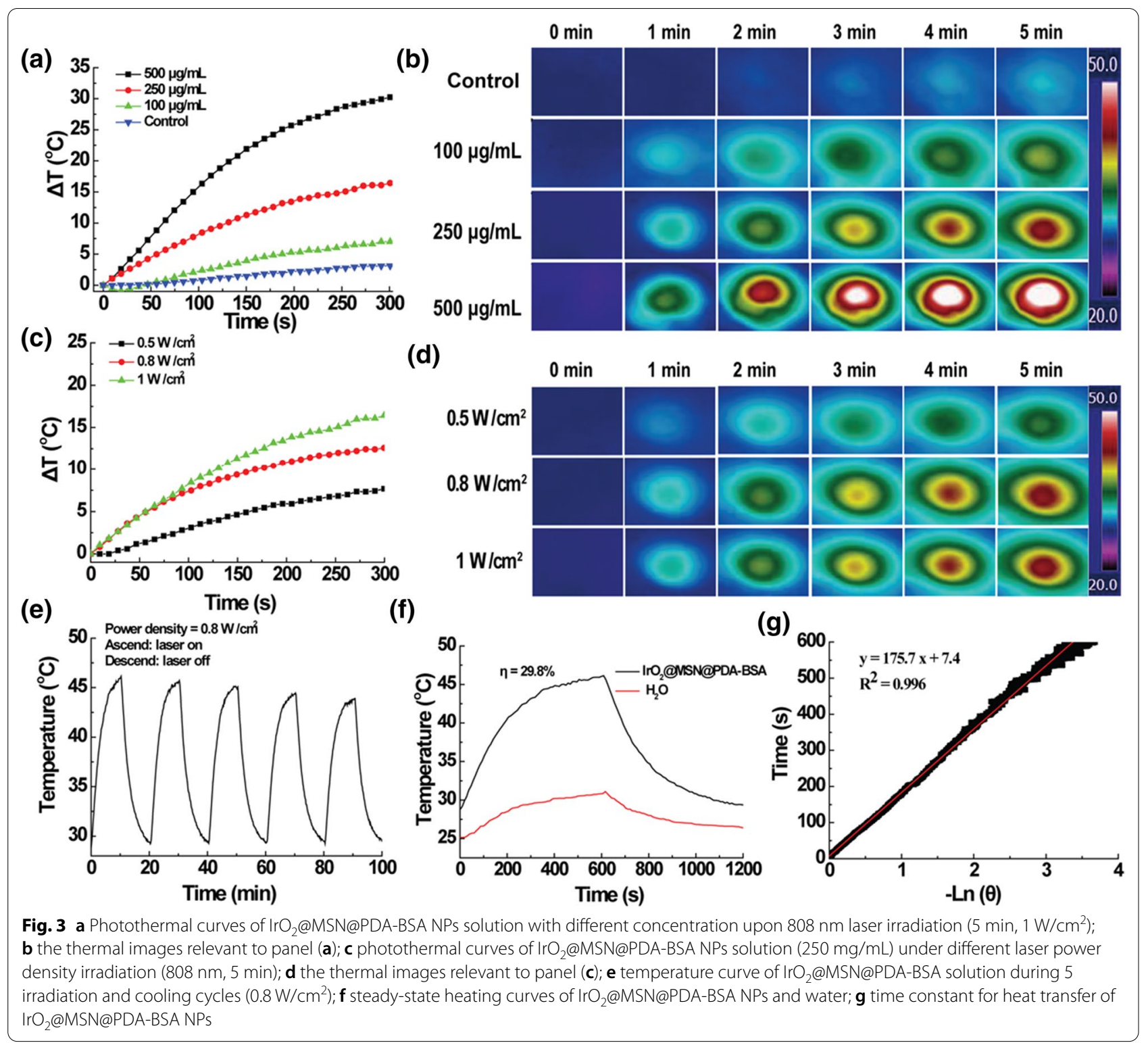

as shown in the CCK-8 results depicted in Fig. 4a. There were no evident differences between the abovementioned sample and the control group. These trends are similar to the results of CCK- 8 and calcein-AM/PI double staining, which stained the live cells and dead cells green and red, respectively (Fig. 4b-f). This indicates that there were no obvious differences between the results of the experimental and control groups after culturing the samples for $24 \mathrm{~h}$. These results indicate that the cytocompatibility of $\mathrm{IrO}_{2} @ M S N @ P D A-B S A(\mathrm{Ce} 6)$ is satisfactory within experimental dosages. The hemocompatibility of $\mathrm{IrO}_{2} @$ MSN@PDA-BSA(Ce6) was evaluated using a hemolysis assay. The HP of $\mathrm{IrO}_{2} @ \mathrm{MSN} @ \mathrm{PDA}-\mathrm{BSA}(\mathrm{Ce} 6)$ remained lower than $5 \%$, even at a high material concentration of
$500 \mu \mathrm{g} / \mathrm{mL}$. The $\mathrm{HP}$ values were equal to $0.4 \pm 0.14 \%$, $1.2 \pm 0.25 \%$, and $2.16 \pm 0.3 \%$ at $\mathrm{IrO}_{2} @ \mathrm{MSN} @ \mathrm{PDA}-$ $\mathrm{BSA}(\mathrm{Ce} 6)$ concentrations of 100,250 , and $500 \mu \mathrm{g} / \mathrm{mL}$, respectively (Fig. $4 \mathrm{~g}$ ). In addition, the $\mathrm{mRBCs}$ of the control and experimental groups were completely separated from the solution with relative ease, whereas the mRBCs in the positive control were completely ruptured (Fig. 4h). The hemolysis assay indicated that the NPs had a minimal impact on the structural integrity of mRBCs, thereby ensuring the safety of intravenous material injections.

\section{In vivo biocompatibility and biodistribution}

The biocompatibility of $\mathrm{IrO}_{2} @ M S N @ P D A-B S A(C e 6)$ in animals was also studied. The body weights of mice 


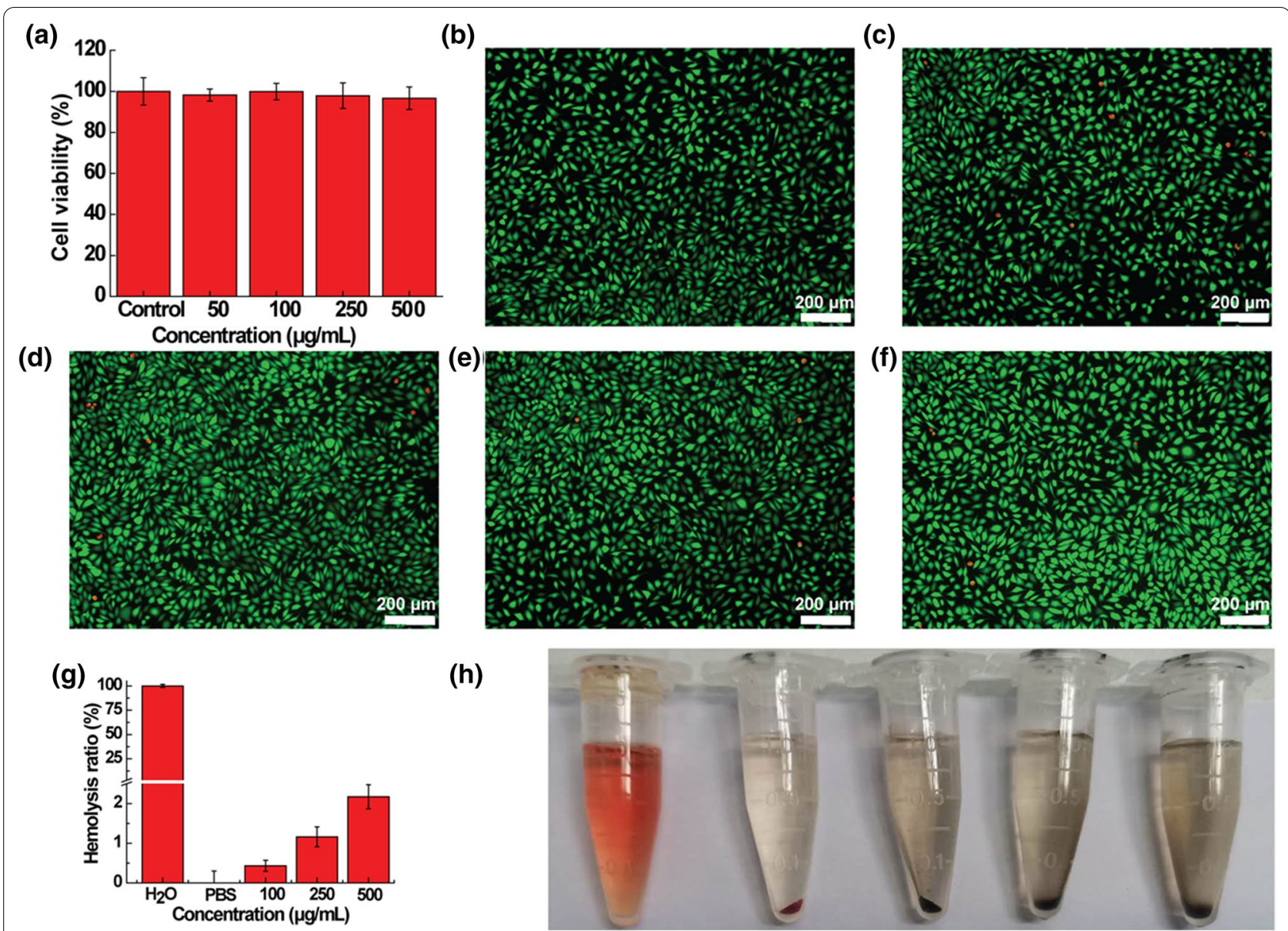

Fig. 4 a L929 cells viabilities after cultured with different concentrations of $1 \mathrm{rO}_{2} @ M S N @ P D A-B S A(C e 6) ; \mathbf{b}-\mathbf{f}$ the photographs of Live/Dead staining relevant to $(\mathbf{a}) ; \mathbf{g}$ hemolytic assay of $1 \mathrm{IO}_{2} @ M S N @ P D A-B S A(C e 6) ; \mathbf{h}$ the photographic images relevant to $(\mathbf{g})$

were measured every 2 days after the I.V. materials injection. The body weights of the experimental and control groups did not differ significantly $(\mathrm{p}>0.05)$, as shown in Fig. 5a. However, the blood routine (Additional file 1: Fig. S6) and serum biochemistry parameters (Fig. 5b) of the mice administered with $\mathrm{IrO}_{2} @ \mathrm{MSN} @ P D A-B S A(\mathrm{Ce} 6)$ were not similar to those of the control group ( $>0.05$ ). The potential toxicity of $\mathrm{IrO}_{2} @ \mathrm{MSN} @ \mathrm{PDA}-\mathrm{BSA}(\mathrm{Ce} 6)$ to vital organs, such as the heart, liver, spleen, lungs, and kidneys, was also evaluated. The H\&E staining of these organs demonstrated that no obvious damage was caused during the preset feeding periods (1, 7 , and 28 days). This indicates that $\mathrm{IrO}_{2} @ M S N @ P D A-B S A(\mathrm{Ce} 6)$ does not cause acute or chronic organ damage. The potential metabolic pathway of $\mathrm{IrO}_{2} @ \mathrm{MSN} @ \mathrm{PDA}-\mathrm{BSA}(\mathrm{Ce} 6)$ was then investigated by conducting an in vivo biodistribution of $\mathrm{Si}$ ions. The accumulation of $\mathrm{Si}$ in the liver and kidney 1 day after the injection was higher than that observed in the other organs due to the non-specific uptake of the reticuloendothelial system. The amount of $\mathrm{Si}$ in the major organs gradually decreased with time. As a result, the concentration of $\mathrm{Si}$ in the tested organs was lower than $5 \mu \mathrm{g} / \mathrm{g} 28$ days after the injection.

\section{In vitro PTT/PDT tumor therapy}

The efficiency of the combined tumor therapy in HT-29 cells and tumor-bearing nude mice was studied to realize the desirable biocompatibility of $\mathrm{IrO}_{2} @$ MSN@PDA-BSA(Ce6) in vitro and in vivo. The HT-29 cells cultured with $\mathrm{IrO}_{2} @ \mathrm{MSN} @ P D A-B S A(\mathrm{Ce} 6)$ in the absence of light intervention did not report excessive cell death. However, the survival rate of the cells after being subjected to $808 \mathrm{~nm}$ NIR laser irradiation was reduced to $48.9 \%(* * * \mathrm{p}<0.001$, versus control, Fig. 6a) due to the excellent photothermal conversion ability of $\mathrm{IrO}_{2} @ \mathrm{MSN} @ P D A-B S A(\mathrm{Ce} 6)$. In comparison with the control group, the viability of the HT-29 cells irradiated with a $660 \mathrm{~nm}$ laser decreased to $65.8 \%$ (PDT group, ${ }^{* * *} \mathrm{p}<0.001$, versus control). The addition of $\mathrm{H}_{2} \mathrm{O}_{2}$ to the DMEM under conditions similar to those 


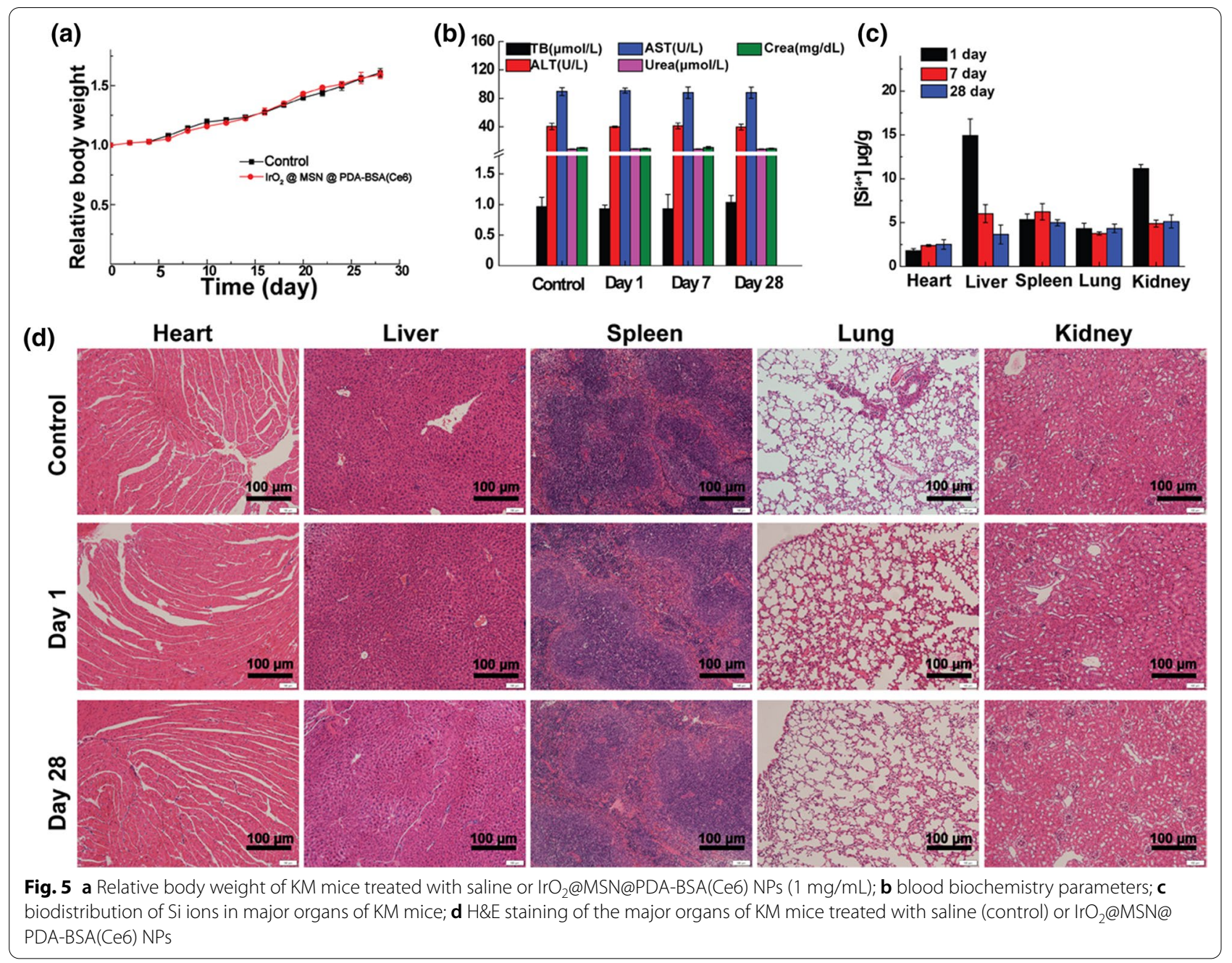

of the PDT group drastically reduced the viability of the HT-29 cells to $17.6 \%\left({ }^{* * * *} \mathrm{p}<0.001\right.$, versus control; *** $\mathrm{p}<0.001$, versus PDT). The differences in the cell viability values indicate that the co-existence of $\mathrm{H}_{2} \mathrm{O}_{2}$ and $\mathrm{IrO}_{2} @ M S N @ P D A-B S A(\mathrm{Ce} 6)$ could enhance the tumor PDT effect. This is because $\mathrm{IrO}_{2}$ catalyzed the decomposition of $\mathrm{H}_{2} \mathrm{O}_{2}$ to produce endogenous oxygen, which was further sensitized by the Ce6 while being irradiated by a $660 \mathrm{~nm}$ laser. Owing to the PTT and CATmimicking abilities of $\mathrm{IrO}_{2} @ \mathrm{MSN} @ P D A-B S A(\mathrm{Ce} 6)$, the HT-29 cells were almost completely dead after being irradiated by the $808 \mathrm{~nm}$ and $660 \mathrm{~nm}$ lasers successively $\left({ }^{* * * * *} \mathrm{p}<0.001\right.$, versus control). The results of the calceinAM/PI Live/Dead staining were similar to those of the CCK-8 cell viability assay. The HT- 29 cells in the control group were stained with a strong green fluorescence, whereas most HT-29 cells treated with PTT, PDT, enhanced PDT, and PDT/PTT were stained red (Fig. 6b-f). This validates the in vitro therapeutic effect of $\mathrm{IrO}_{2} @ \mathrm{MSN} @ \mathrm{PDA}-\mathrm{BSA}(\mathrm{Ce} 6)$.

\section{In vivo combined tumor therapy}

The in vitro therapeutic effect investigation provides preliminary confirmation that $\mathrm{IrO}_{2} @ M S N @ P D A-$ $\mathrm{BSA}(\mathrm{Ce} 6)$ is suitable for multimodal tumor therapy. This was verified by the tests conducted on animals. The variations in the temperatures of the tumorbearing nude mice that received the material injections were measured using a thermal imaging camera. The $\Delta \mathrm{T}$ of the control group was only $4.3{ }^{\circ} \mathrm{C}$ after being subjected to NIR irradiation at $808 \mathrm{~mm}$ ( $5 \mathrm{~min}$ ), whereas $\Delta \mathrm{T}$ for the mice injected with the I.V. and I.T. materials were 10.3 and $20.8{ }^{\circ} \mathrm{C}$, respectively. The variation in the temperatures of the mice injected with the I.V. material also proved that $\mathrm{IrO}_{2} @ M S N @ P D A-$ BSA(Ce6) could passively accumulate at the tumor site through the EPR effect. The volume of the tumors of the mice belonging to the control group increased to 9.12 times their original values after 28 days of feeding. However, the tumor volumes of the PTT group increased to 2.56 times their original values 


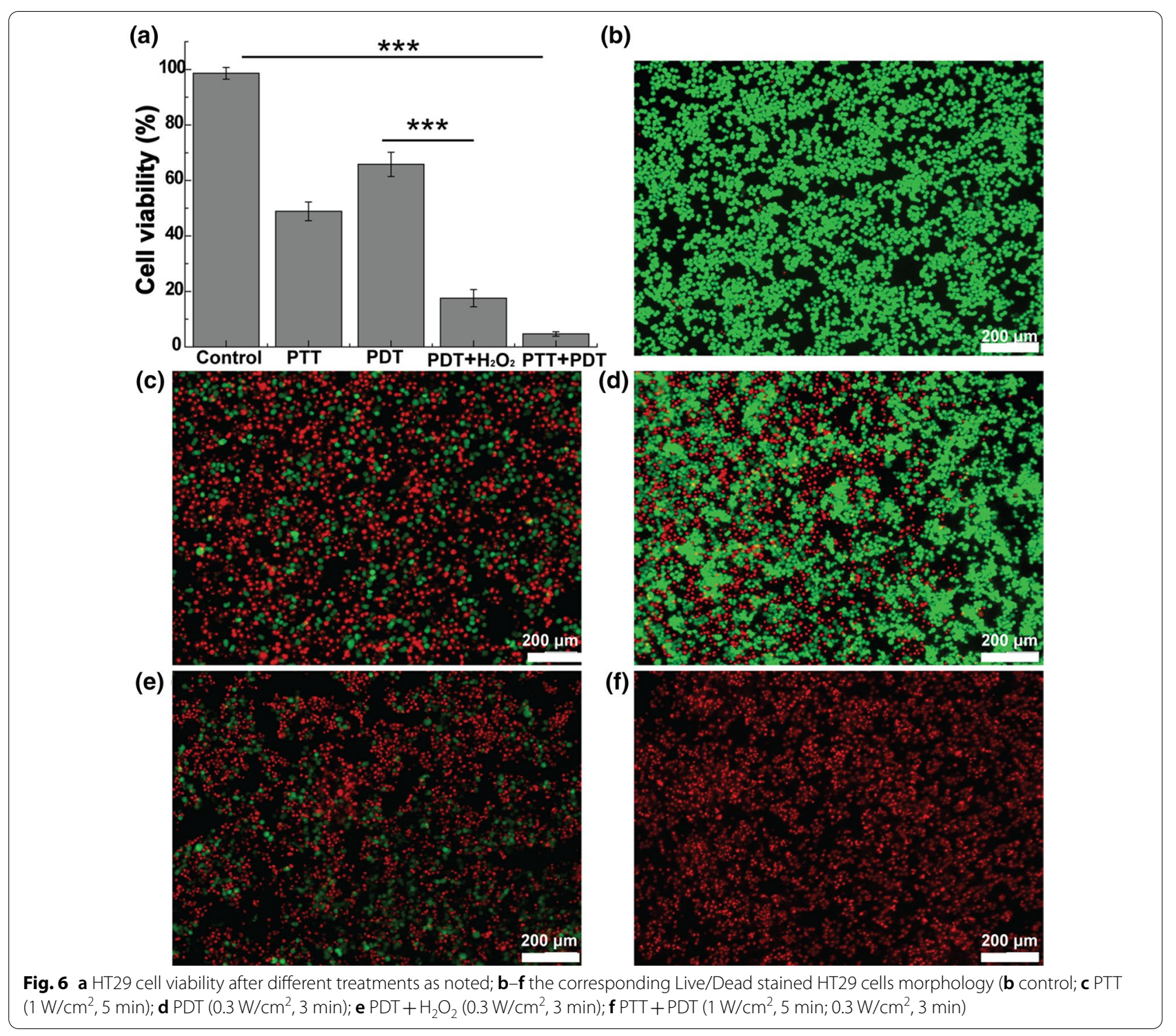

$\left({ }^{* * * *} \mathrm{p}<0.001\right.$, versus control). This indicates that PTT can kill a few cancer cells while the surviving ones continue to grow. Similarly, the tumor volumes of the PDT group increased to approximately 3.42 times their original values $\left({ }^{* * * *} \mathrm{p}<0.001\right.$, versus control). There was no obvious difference between the tumor volumes of the PDT and PTT groups ( $>>0.05)$. This suggests that a single dose of PTT or PDT produces a certain therapeutic effect. However, the tumors of the mice in the combined therapy group were completely eradicated, irrespective of the material injection method (Fig. 7c, d). This confirms the superior efficiency of the combined tumor therapy of the $\mathrm{IrO}_{2} @ \mathrm{MSN} @ P D A-$ BSA(Ce6) NPs.

\section{Conclusions}

An IrO $\mathrm{O}_{2} @ M S N @ P D A-B S A(\mathrm{Ce} 6)$ nanoenzymatic composite platform for the treatment of tumors through the combined effects of PTT and PDT was designed in this study. The MSN coating introduced abundant pores for Ce6 loading, and the conjugated BSA endowed the NPs with sufficient biocompatibility in vitro and in vivo. The loading of Ce6 facilitated the photo-triggered generation of single oxygen, resulting in photodynamic cell death. $\mathrm{IrO}_{2}$ functions as a CAT-mimic to catalyze the decomposition of $\mathrm{H}_{2} \mathrm{O}_{2}$ in the TME to generate endogenous oxygen and alleviate the hypoxia of solid tumors. This enhances the PDT of Ce6 by offering local oxygen and promoting the generation of ${ }^{1} \mathrm{O}_{2}$. In addition, the 


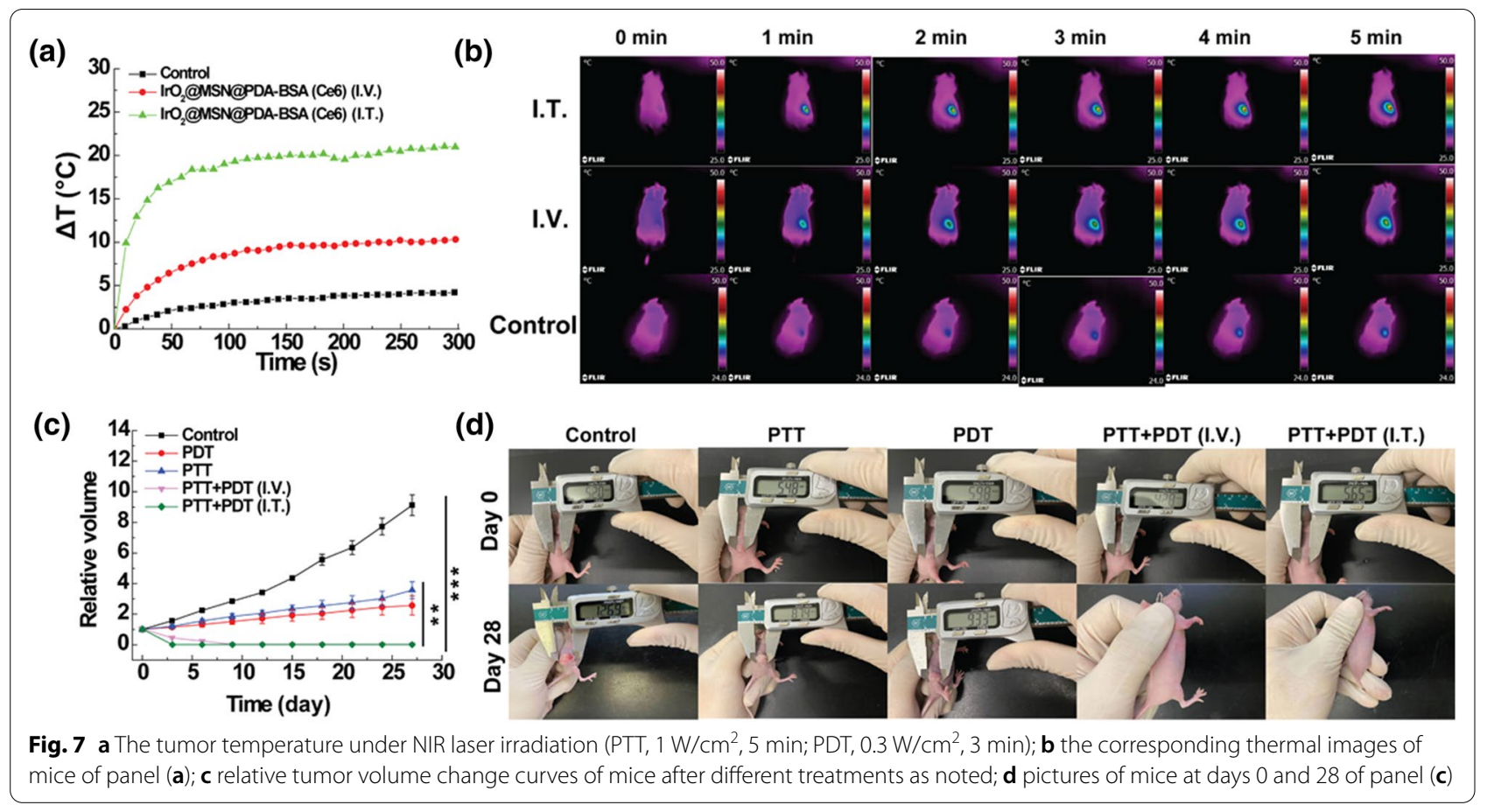

PDA coating and $\mathrm{IrO}_{2}$ NPs exhibited remarkably high photothermal conversion efficiencies, resulting in the ablation of solid tumors through hyperthermia. The therapeutic effect of $\mathrm{IrO}_{2} @ \mathrm{MSN} @ P D A-B S A(\mathrm{Ce} 6)$ for multimodal tumor therapy was proved both in vitro and in vivo. The results indicated that the tumors of the mice in the combined therapy group could be completely eradicated. The findings of the present study highlight the feasibility of using theranostic nanoenzymes for translational medicine.

\section{Supplementary Information}

The online version contains supplementary material available at https://doi. org/10.1186/s12951-021-00948-8.

Additional file 1. 1. Materials. 2. Characterization of $1 \mathrm{rO} \mathrm{O}_{2} @ M S N @ P D A-B S A$ NPs. Fig. S1. (a) The TEM images of $\mathrm{Ir}_{2} @ M S N @ P D A-B S A N P$; $(b)$ the corresponding size distributions of $\mathrm{IrO}_{2}-\mathrm{PVP}$ nanoparticles. Fig. S2. EDS spectra of IrO $2_{2} @ M S N @ P D A-B S A$ NPs. Fig. S3. FTIR spectra of PVP, PDA, and IrO $@$ @MSN@PDA-BSA NPs. Fig. S4. Release of Ce6 from IrO $\mathrm{O}_{2} @ M S N @$ PDA-BSA(Ce6) NPs. Fig. S5. Variation of the dissolved oxygen (DO) content at different pH values (pH 6.0 and 7.4). Fig. S6. Routine blood test of $1 \mathrm{rO}_{2} @$ MSN@PDA-BSA(Ce6) treated KM mice fed for different days.

\section{Acknowledgements}

H. W. and Q. J. contributed equally to this work. This research is financially supported by Shanghai Sailing Program 20YF1448400, Naval Medical University Sailing Program 2019-QH-16, Shanghai Changhai Hospital Youth Found.

\section{Authors' contributions}

HW and QJ designed and performed the experiment, and wrote the manuscript. KL, CZ, MX and SW analyzed the data. ZF and JZ supervised the research. All authors read and approved the final manuscript.

\section{Funding}

Not applicable.

Availability of data and materials

All data generated or analyzed during this study are included in this manuscript and its additional material.

\section{Declarations}

Ethics approval and consent to participate Not applicable.

\section{Consent for publication}

Not applicable.

\section{Competing interests}

All authors declare that they have no conflict of interest or financial conflicts to disclose.

\section{Author details}

${ }^{1}$ Department of Breast Surgery, Xinhua Hospital, Shanghai Jiaotong University School of Medicine, No. 1665 Kongjiang Road, Shanghai 200433, People's Republic of China. . ${ }^{2}$ Department of Gastroenterology, Changhai Hospital, Second Military Medical University, No. 168 Changhai Road, Shanghai 200433, People's Republic of China. ${ }^{3}$ College of Science, University of Shanghai for Science and Technology, No. 334 Jungong Road, Shanghai 200093, People's Republic of China.

Received: 29 March 2021 Accepted: 29 June 2021

Published online: 07 July 2021 


\section{References}

1. Siegel RL, Miller KD, Fuchs HE, Jemal A. Cancer statistics, 2021. CA Cancer J Clin. 2021;71:7-33.

2. Zeng H, Chen W, Zheng R, Zhang S, Ji JS, Zou X, Xia C, Sun K, Yang Z, $\mathrm{Li} \mathrm{H}$, et al. Changing cancer survival in China during 2003-15: a pooled analysis of 17 population-based cancer registries. Lancet Glob Health. 2018:6:e555-67.

3. Vasan $\mathrm{N}$, Baselga J, Hyman DM. A view on drug resistance in cancer. Nature. 2019:575:299-309.

4. Herrmann J. Adverse cardiac effects of cancer therapies: cardiotoxicity and arrhythmia. Nat Rev Cardiol. 2020;17:474-502.

5. Liu Y, Bhattarai P, Dai Z, Chen X. Photothermal therapy and photoacoustic imaging via nanotheranostics in fighting cancer. Chem Soc Rev. 2019:48:2053-108.

6. Liu S, Pan X, Liu H. Two-dimensional nanomaterials for photothermal therapy. Angew Chem Int Ed Engl. 2020;59:5890-900.

7. Monro S, Colon KL, Yin H, Roque J, Konda P, Gujar S, Thummel RP, Lilge L, Cameron CG, McFarland SA. Transition metal complexes and photodynamic therapy from a tumor-centered approach: challenges, opportunities, and highlights from the development of TLD1433. Chem Rev. 2019;119:797-828.

8. Yang J, Hou M, Sun W, Wu Q, Xu J, Xiong L, Chai Y, Liu Y, Yu M, Wang H, et al. Sequential PDT and PTT using dual-modal single-walled carbon nanohorns synergistically promote systemic immune responses against tumor metastasis and relapse. Adv Sci (Weinh). 2020;7:2001088.

9. Liang R, Liu L, He H, Chen Z, Han Z, Luo Z, Wu Z, Zheng M, Ma Y, Cai $L$. Oxygen-boosted immunogenic photodynamic therapy with gold nanocages@manganese dioxide to inhibit tumor growth and metastases. Biomaterials. 2018;177:149-60.

10. Liu P, Xie X, Shi X, Peng Y, Ding J, Zhou W. Oxygen-self-supplying and HIF1alpha-Inhibiting core-shell nanosystem for hypoxia-resistant photodynamic therapy. ACS Appl Mater Interfaces. 2019;11:48261-70.

11. Luo K, Wu H, Chen Y, Li J, Zhou L, Yang F, Huang M, An X, Wang S. Preparation of Bi-based hydrogel for multi-modal tumor therapy. Colloids Surf B Biointerfaces. 2021;200:111591.

12. Pucelik B, Sulek A, Barzowska A, Dabrowski JM. Recent advances in strategies for overcoming hypoxia in photodynamic therapy of cancer. Cancer Lett. 2020;492:116-35.

13. Cheng Y, Cheng H, Jiang C, Qiu X, Wang K, Huan W, Yuan A, Wu J, Hu Y. Perfluorocarbon nanoparticles enhance reactive oxygen levels and tumour growth inhibition in photodynamic therapy. Nat Commun. 2015:6:8785.

14. Chang M, Hou Z, Wang M, Wang M, Dang P, Liu J, Shu M, Ding B, Al Kheraif AA, Li C, Lin J. Cu2 MoS4 /Au heterostructures with enhanced catalase-like activity and photoconversion efficiency for primary/metastatic tumors eradication by phototherapy-induced immunotherapy. Small. 2020;16:e1907146.

15. Shen J, Rees TW, Zhou Z, Yang S, Ji L, Chao H. A mitochondria-targeting magnetothermogenic nanozyme for magnet-induced synergistic cancer therapy. Biomaterials. 2020;251:120079.

16. Cheng X, He L, Xu J, Fang Q, Yang L, Xue Y, Wang X, Tang R. Oxygenproducing catalase-based prodrug nanoparticles overcoming resistance in hypoxia-mediated chemo-photodynamic therapy. Acta Biomater. 2020;112:234-49.

17. Sahu A, Min K, Jeon J, Yang HS, Tae G. Catalytic nanographene oxide with hemin for enhanced photodynamic therapy. J Control Release. 2020;326:442-54

18. Wu J, Wang $X$, Wang $Q$, Lou Z, Li S, Zhu Y, Qin L, Wei H. Nanomaterials with enzyme-like characteristics (nanozymes): next-generation artificia enzymes (II). Chem Soc Rev. 2019:48:1004-76.

19. Jiang D, Ni D, Rosenkrans ZT, Huang P, Yan X, Cai W. Nanozyme: new horizons for responsive biomedical applications. Chem Soc Rev. 2019:48:3683-704.
20. Hou X, Tao Y, Pang Y, Li X, Jiang G, Liu Y. Nanoparticle-based photothermal and photodynamic immunotherapy for tumor treatment. Int J Cancer. 2018;143:3050-60.

21. Nam J, Son S, Ochyl LJ, Kuai R, Schwendeman A, Moon JJ. Chemophotothermal therapy combination elicits anti-tumor immunity against advanced metastatic cancer. Nat Commun. 2018;9:1074.

22. Hu K, Xie L, Zhang Y, Hanyu M, Yang Z, Nagatsu K, Suzuki H, Ouyang J, Ji X, Wei J, et al. Marriage of black phosphorus and $\mathrm{Cu}(2+)$ as effective photothermal agents for PET-guided combination cancer therapy. Nat Commun. 2020;11:2778

23. Murugan C, Sharma V, Murugan RK, Malaimegu G, Sundaramurthy A Two-dimensional cancer theranostic nanomaterials: synthesis, surface functionalization and applications in photothermal therapy. J Control Release. 2019:299:1-20.

24. Zhang Y, Lv F, Cheng Y, Yuan Z, Yang F, Liu C, Cao Y, Zhang K, Lu H, Zada S, et al.Pd@Au bimetallic nanoplates decorated mesoporous MnO2 for synergistic nucleus-targeted NIR-II photothermal and hypoxia-relieved photodynamic therapy. Adv Healthc Mater. 2020;9:e1901528.

25. Chen G, Ma B, Wang Y, Xie R, Li C, Dou K, Gong S. CuS-based theranostic micelles for NIR-controlled combination chemotherapy and photothermal therapy and photoacoustic imaging. ACS Appl Mater Interfaces. 2017:9:41700-11.

26. Rong L, Zhang Y, Li WS, Su Z, Fadhil Jl, Zhang C. Iron chelated melaninlike nanoparticles for tumor-associated macrophage repolarization and cancer therapy. Biomaterials. 2019;225:119515.

27. Sun W, Du Y, Liang X, Yu C, Fang J, Lu W, Guo X, Tian J, Jin Y, Zheng J. Synergistic triple-combination therapy with hyaluronic acid-shelled PPy/CPT nanoparticles results in tumor regression and prevents tumor recurrence and metastasis in 4T1 breast cancer. Biomaterials. 2019;217:119264.

28. Zhou L, Zhao J, Chen Y, Zheng Y, Li J, Zhao J, Zhang J, Liu Y, Liu X, Wang S. MoS2-ALG-Fe/GOx hydrogel with Fenton catalytic activity for combined cancer photothermal, starvation, and chemodynamic therapy. Colloids Surf B Biointerfaces. 2020;195:111243.

29. Wan G, Chen B, Li L, Wang D, Shi S, Zhang T, Wang Y, Zhang L, Wang Y. Nanoscaled red blood cells facilitate breast cancer treatment by combining photothermal/photodynamic therapy and chemotherapy. Biomaterials. 2018;155:25-40

30. Ferroni C, Del Rio A, Martini C, Manoni E, Varchi G. Light-Induced therapies for prostate cancer treatment. Front Chem. 2019;7:719

31. Sun W, Zhao X, Fan J, Du J, Peng X. Boron dipyrromethene nano-photosensitizers for anticancer phototherapies. Small. 2019;15:e1804927.

32. Gu W, Zhang T, Gao J, Wang Y, Li D, Zhao Z, Jiang B, Dong Z, Liu H. Albumin-bioinspired iridium oxide nanoplatform with high photothermal conversion efficiency for synergistic chemo-photothermal of osteosarcoma. Drug Deliv. 2019;26:918-27.

33. Zhen W, Liu Y, Lin L, Bai J, Jia X, Tian H, Jiang X. BSA-IrO2: catalase-like nanoparticles with high photothermal conversion efficiency and a high $X$-ray absorption coefficient for anti-inflammation and antitumor theranostics. Angew Chem Int Ed Engl. 2018:57:10309-13.

34. Gulzar A, Xu J, Yang D, Xu L, He F, Gai S, Yang P. Nano-graphene oxide-UCNP-Ce6 covalently constructed nanocomposites for NIRmediated bioimaging and PTT/PDT combinatorial therapy. Dalton Trans. 2018:47:3931-9.

35. Wan S, Zhang B, Li S, He B, Pu Y. Combination of PEG-decorated black phosphorus nanosheets and immunoadjuvant for photoimmunotherapy of melanoma. J Mater Chem B. 2020;8:2805-13.

\section{Publisher's Note}

Springer Nature remains neutral with regard to jurisdictional claims in published maps and institutional affiliations. 